\title{
The mathematics of Crohn disease
}

Cite as: CMAJ 2018 September 24;190:E1143. doi: 10.1503/cmaj.180764

Curled up like a sow bug in retreat, map in hand, he is calculating the distance from his couch

to the store, circling the pinpoints of known or surmised available bathrooms.

He's assaying the time between bouts of seizing, ignited guts. It's been days

since he felt wind sting his eyes, tears being his secret talisman of health.

His work hours are honed and divided. Refusing taboo, he's informed his students the square root of disease is mutation and mutation is a statistical entity,

though it doesn't imply disease...

the opposite of "mutant" is not "normal" but "wild type." Not a badger or wolverine,

but wild as in preponderance of the similar, as in, the many three-leaf clovers.

With luck, what can't be controlled is kept out of sight. He tries to escape

rank memories that shrink him to a baby: a caretaker handling him roughly,

her nose wrinkled and breath held, a voice mewling eeww, memories that cinch him into a corner shrouded in shame. So much that is indigestible,

like the soil from coiled ropes of his colon-

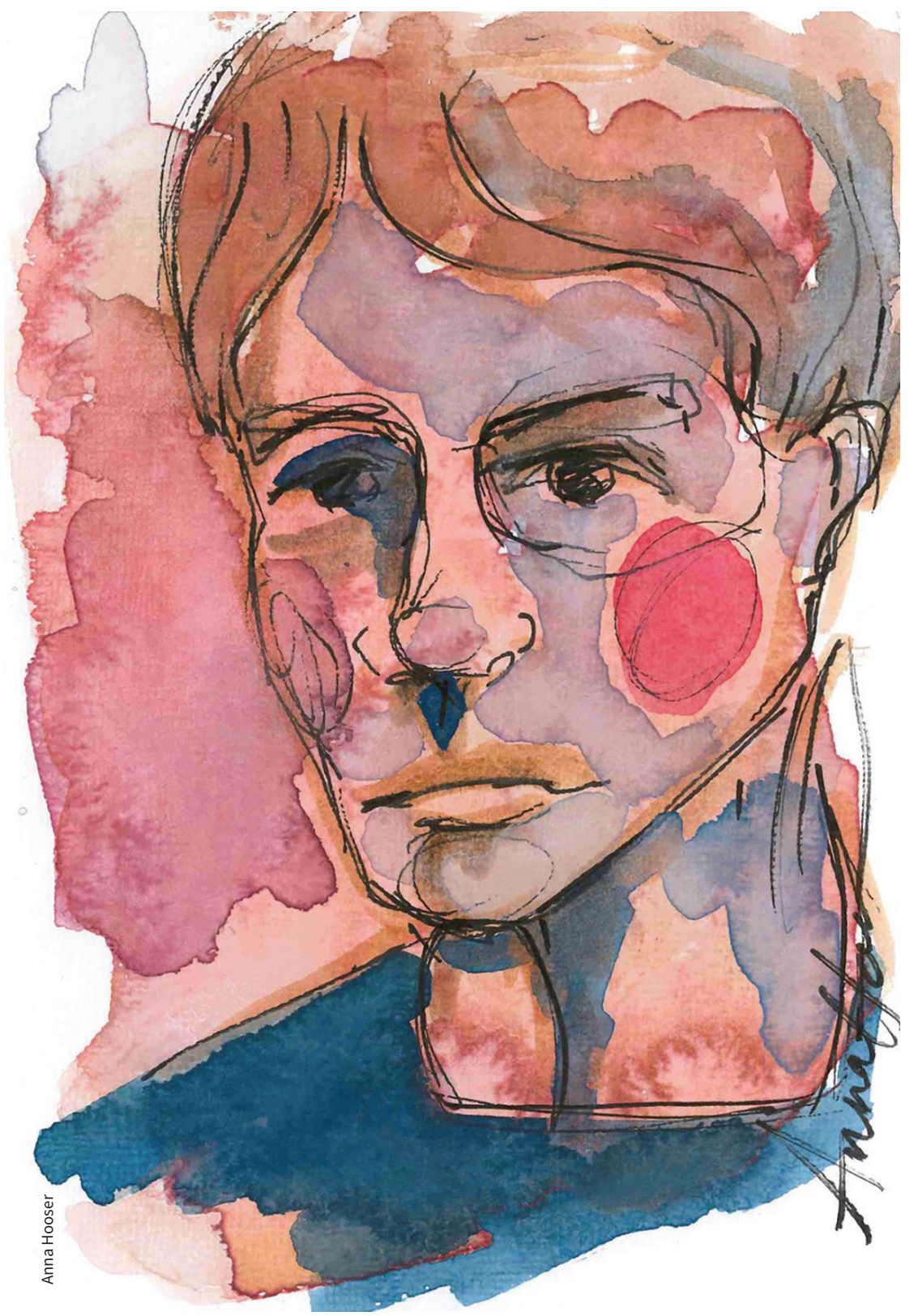

\section{Suzanne Edison MA MFA}

Seattle, Wash.

Quoted words and phrases and those in italics are taken from The gene: an intimate history by Siddartha Mukherjee (Scribner, 2016).

This article has not been peer reviewed. 